\title{
Maritime Transportation of Illegal Drugs from South America
}

- Michael P. Atkinson: Operations Research Department, Naval Postgraduate School, Monterey, CA, 93943,mpatkins@nps.edu

- Moshe Kress: Operations Research Department, Naval Postgraduate School, Monterey, CA, 93943, mkress@nps.edu

- Roberto Szechtman: Operations Research Department, Naval Postgraduate School, Monterey, CA, 93943,rszechtm@nps.edu 


\title{
Maritime Transportation of Illegal Drugs from South America
}

\begin{abstract}
The US invests considerable effort in searching and interdicting drug-trafficking vessels in the Caribbean and Eastern Pacific regions. While some vessels are indeed interdicted, resulting in confiscation of substantial quantities of drugs, many such vessels manage to avoid detection and arrive safely at their destinations in Central America and Mexico with their drug load intact. The agency in charge of interdicting this traffic, Joint Interagency Task Force South - JIATF-S, sends out both aerial and surface assets for search and interdiction missions. An important parameter for planning such missions is an estimate of the expected steady-state number of the various types of vessels present in the search regions at any given time. In this paper we use various sources to estimate these numbers. We estimate that the number of shipments initiated per month ranges between four and six dozen, and at any given time there are between two and four vessels, of all types, on the high seas.
\end{abstract}

\section{Introduction}

One of primary missions of the US Southern Command (USSOUTHCOM) is to disrupt the flow of drugs from Central and South America to the United States via the southern approaches. This mission is executed by the Joint Interagency Task Force South - JIATF-S. JIATF-S is a US-government interagency that collaborates with law-enforcement agencies from other countries in Central America. Drug Trafficking Organizations (DTOs) employ both maritime and air conveyances and use a variety of vessel types to transport the drugs. Examples of maritime means of transportation include go-fast boats, pangas, fishing vessels, and self-propelled semi-submersibles (SPSS). JIATF-S's area of operations (AO) covers over 42 million square miles (Stavridis 2010; Office of National Drug Control Policy[ONDCP] 2014), yet it has quite a limited fleet of search and interdiction assets to effectively support its mission. 
Notwithstanding lead-times in the drug supply chain, a reasonable and simple estimate for the nonintercepted flow of cocaine from South America to the US in a given time period is the estimated total consumption of cocaine during that time in the US. If the total consumption is $X$, and there are no other significant sources of cocaine shipped to the US, then the total flow of cocaine to the US in that period is $X$ too. Estimates of drug consumption are given in Kilmer et al. (2014); ONDCP (2010, 2012, 2013, 2014); Caulkins et al. (2015); Rhodes et al. (2012); and United Nations Office on Drugs and Crime [UNODC] (2011).However, we must be cautious using this estimate. First, the purity of cocaine decreases as it moves through the supply chain down to the consumers. Thus, $X$ tons of cocaine in the streets of US cities may be generated from only $Y$ tons of shipped cocaine of higher purity, where $Y<X$. Second, nearly all the cocaine exported from South America to the rest of the world flows through the Caribbean and Eastern Pacific regions, and thus we cannot merely focus on US consumption estimates. The main question we address in this work relates to the interdiction efforts of JIATF-S: how many cocainecarrying vessels of a certain type are afloat in the area of interest at any given time? This number is affected by the number and capacity of the various vessels, production capacities and processing schedules of cocaine at the sources in South America, logistic constraints regarding ground transportation, weather, and possibly seasonality in demand for cocaine. The number of vessels and their spatial distribution in the area are also affected by the actions of the interdicting force - JIATF-S. The latter consideration lends itself to a game-theoretic situation. This paper aims at estimating the DTO traffic intensity at sea by focusing on the maritime transportation section of the DTO supply chain. Here we take an aggregate approach by considering both production and consumption data to constitute the base for estimating total DTO traffic in the maritime Caribbean and Eastern Pacific. In particular, we ignore possible responses of DTOs to interdiction efforts by JIATF-S. To simplify exposition we henceforth call JIATF-S the interdictor. 


\section{DTO Traffic Estimates}

As mentioned in the Introduction, we plan to answer the following question: how many drug-carrying DTO vessels of a certain type are afloat in the $\mathrm{AO}$ at any given time? The challenge is to estimate an unobservable parameter (undetected vessels) based on limited available data regarding production, consumption, and interdiction. From the point of view of the interdictor, each DTO vessel is in one of three possible states: interdicted, known but not interdicted, and unknown. A vessel in the state known but not interdicted is a vessel whose existence, and perhaps its whereabouts, are known to some agency such as FBI, CIA, DEA, local law enforcement, or partner nations, but interdiction does not occur for various reasons (e.g., the information is not passed to the interdictor in sufficient time). The primary challenge, however, is estimating the unknown category. The Consolidated Counterdrug Database (CCDB) tracks some of these shipments and labels them as either confirmed (seizures), substantiated, or suspect (Kilmer et al. 2014). The suspect category may be a rough proxy for some of the unknown traffic flow, however some of the events in the suspect category may include drug shipments that do not actually exist. See section 7.1.3.3 in Kilmer et al. (2014) for a more in-depth discussion of the uncertainty associated with using the data in the CCDB. Rather than work directly with the data in the CCDB and attempt to correct for possible under and over counting, we start our analysis at a more aggregate level by considering production and consumption data. First we construct an estimate of the cocaine departing Colombia via maritime conveyances. Then we use information on routes and vessels used by DTOs to estimate the number of vessels transiting the $\mathrm{AO}$ at any given time. We limit ourselves to data from unclassified sources. Much more detailed, but classified, data exists in the CCDB and other government sources. The methodology presented in this paper may be applied to those classified sources to obtain more refined estimates. We focus our attention on four types of vessels: go-fast boats, SPSS, fishing vessels, and pangas. Go-fast boats are small, agile and powerful boats that can go as fast as 80 knots in calm waters. Self-propelled semi-submersibles (SPSS) (aka narco-subs) are custom-made vessels that cannot dive but can submerge such that only the cockpit and the exhaust gas pipe stay above water. Pangas are modest- 
sized outboard-powered boats mostly used for coastal fishing. We consider three smuggling corridors from the northern part of South America: the Eastern Pacific (EastPac), the Western Caribbean (WCarib), and the Eastern Caribbean (ECarib). EastPac and WCarib consist of routes heading to the western and eastern coasts of Central America, respectively, while ECarib contains routes heading toward Caribbean islands such as Jamaica, Hispaniola, and Puerto Rico. The reference to these three aggregate corridors stem from the available data; if more detailed route information becomes available (e.g., information about specific departure and arrival zones along each corridor), we could enhance our analysis to account for this level of detail. Our main result is that, based on the available data covering the years 2009-2012, one would expect about 57 maritime shipments launched per month across all corridors and vessel-types. More specifically, at any particular time an average of 2.5 drug-smuggling vessels, of all types, are present on the water in the $\mathrm{AO}$. We present point estimates - rather than confidence intervals - because the available data is limited to only rough estimates of mean values. There is insufficient data to estimate statistical distributions or even variances of relevant random variables. We do perform extensive sensitivity analysis in Section 3. Whenever we need to make operational assumptions we assume a worstcase scenario from the point of view of the interdictor. To compute these estimates we consider the following inputs.

1. Amount of export quality cocaine leaving South American each year.

2. Fraction of exported cocaine that transits via maritime conveyances in the AO.

3. Fraction of cocaine that traverses along each of the three corridors.

4. Average distance traveled by smugglers along maritime routes for each of the three corridors.

5. Fraction of cocaine carried on each of the four types of vessels.

6. Velocity of each of the four vessel-types.

7. Drug-capacity of each of the four vessel-types.

8. Average time to traverse each corridor by vessel-type.

The baseline for the aforementioned estimations is discussed in the Appendix. 
We present up front our baseline estimates for each one of the aforementioned eight parameters in the following tables. The details behind these estimates and their associated uncertainties appear in the Appendix. Section 3 presents sensitivity analysis.

\begin{tabular}{|c|c|}
\hline Cocaine leaving South America each year & 850 metric tons \\
\hline Fraction of flow on water & 0.9 \\
\hline
\end{tabular}

Table 1: General parameter values

\begin{tabular}{|c|ccc|}
\hline & EastPac & WCarib & ECarib \\
\hline Average distance of route along corridor & $750 \mathrm{~nm}$ & $680 \mathrm{~nm}$ & $500 \mathrm{~nm}$ \\
Fraction of flow along corridor & 0.59 & 0.33 & 0.08 \\
\hline
\end{tabular}

Table 2: Corridor parameters

\begin{tabular}{|c|cccc|}
\hline & Go-fast & SPSS & Fishing & Panga \\
\hline Velocity & $25 \mathrm{kts}$ & $10 \mathrm{kts}$ & $15 \mathrm{kts}$ & $20 \mathrm{kts}$ \\
Capacity & 1 metric ton & 5 metric tons & 1 metric ton & 0.5 metric tons \\
Fraction of flow by vessel-type & 0.74 & 0.18 & 0.03 & 0.05 \\
\hline
\end{tabular}

Table 3: Vessel parameters

\begin{tabular}{|c|ccc|}
\hline & EastPac & WCarib & ECarib \\
\hline Go-fast & 0.38 & 0.28 & 0.08 \\
SPSS & 0.15 & 0.03 & 0.00 \\
Fishing & 0.01 & 0.02 & 0.00 \\
Panga & 0.05 & 0.00 & 0.00 \\
\hline
\end{tabular}

Table 4: Bivariate distribution for cocaine flow by corridor and vessel-type

850 metric tons of export quality cocaine flow out of South America each year. Approximately $10 \%$ of the cocaine transits via air, and we assume that the remaining $90 \%$ transits via the sea. Even the drugs that 
eventually transit to Europe via air, usually travel to an intermediate point first in Central America or the Caribbean (UNODC 2011). Thus, 765 metric tons traverse the water each year, and breaking down this number according to the distribution in Table 4 provides the estimated amount of cocaine that flows on each corridor/vessel-type combination. To determine how many shipments are made each year, we divide the amount of drugs by the average capacity per vessel from Table 3. For example 112 metric tons (765 $\times 0.15)$ flow along the EastPac each year in SPSS. Since each SPSS carries 5 metric tons, that equates to approximately 22 SPSS transits in the EastPac per year, or slightly less than 2 per month. Performing similar calculations yields Table 5 .

\begin{tabular}{|c|ccc|c|}
\hline & EastPac & WCarib & ECarib & \\
\hline Go-fast & 24.4 & 17.9 & 5.0 & 47.3 \\
SPSS & 1.9 & 0.4 & 0.0 & 2.3 \\
Fishing & 0.7 & 1.4 & 0.0 & 2.1 \\
Panga & 5.7 & 0.0 & 0.0 & 5.7 \\
\hline & 32.7 & 19.8 & 5.0 & 57.4 \\
\hline
\end{tabular}

Table 5: Average number of shipments initiated along each corridor per month

We also compute the average number of vessels in the $\mathrm{AO}$ at any given time. The longer it takes to traverse a route, the more vessels we expect to be on the water. We use the velocities in Table 3 and the distances in Table 2 in our calculation. For example, a go-fast traveling $25 \mathrm{kts}$ will traverse the average $750 \mathrm{~nm}$ EastPac route in 30 hours. From Table 5 a go-fast is launched every 0.033 hours $(((24.4) /(30 * 24)))$ along the EastPac, and thus we would expect on average 1.0 go-fasts $(0.033 \times 30)$ along the EastPac corridor at any given time. Similar calculations produce Table 6. 


\begin{tabular}{|c|ccc|c|}
\hline & EastPac & WCarib & ECarib & \\
\hline Go-fast & 1.00 & 0.67 & 0.14 & 1.81 \\
SPSS & 0.19 & 0.04 & 0.00 & 0.23 \\
Fishing & 0.05 & 0.09 & 0.00 & 0.14 \\
Panga & 0.29 & 0.00 & 0.00 & 0.29 \\
\hline & 1.54 & 0.80 & 0.14 & 2.47 \\
\hline
\end{tabular}

Table 6: Average number of vessels along each corridor at any given time

As mentioned earlier, we present the results in Tables 5 and 6 as point estimates, when in reality there is a great deal of uncertainty about the underlying inputs (e.g., velocities, capacities, etc.), and hence in the outputs contained in Tables 5 and 6 . In the next section we thoroughly examine the uncertainty in the inputs and analyze how this impacts the final results. In the future when more accurate information and data are collected, one can update the input estimates in Tables 1--4 and use our methodology to produce more refined results

\section{Sensitivity Analysis}

In this section we perform sensitivity analysis to provide a range of plausible values for the number of smuggling vessels as we vary the parameter estimates. Some sensitivity analysis is very straightforward. For example, any change in our baseline of 850 metric tons flowing out of South America will produce a proportional change in Tables 5 and 6 . In particular, the first decade of the 21 st century saw a sharp decrease in the consumption and flow of cocaine (Kilmer et al. 2014; ONDCP 2014; Rhodes et al. 2012). If the current 2016 value is, for example, $20 \%$ less than the 2012 estimate we use in Table 1, then the values in Tables 5 and 6 will also decrease by $20 \%$, producing an average of 46 shipments initiated per month. A decade ago, some sources estimated the flow of cocaine at nearly 1200 metric tons (Kilmer et al. 2014; ONDCP 2010). Using this estimate would increase the values in Tables 5 and 6 by $41 \%$, 
producing an average of 80 shipments initiated per month. The same logic applies for the fraction of drugs that transit via maritime conveyances. If we use the 0.8 estimate from Table A.2 of the Appendix, then the results in Tables 5 and 6 will decrease by $11 \%$.

As a first step, we generalize the discussion in the previous paragraph by varying all the parameters simultaneously. We perform a Monte Carlo simulation analysis by assuming the parameters in Tables $1-4$ have a uniform distribution with the lower limit set to $50 \%$ of the baseline estimate in Table $1-4$ and the upper limit set to $50 \%$ greater than the baseline estimate. The only exceptions are the fraction of flow on the water (see Table 1), which we vary between 0.8 and 1.0, and the bivariate distribution for cocaine flow by corridor and vessel-type, which we fix to the values in Table 4 . There is no hard data that justifies these distributions; our purpose with this Monte Carlo analysis is to examine how robust the traffic estimates are to significant changes in the underlying inputs. Table 7 contains the results of 100000 simulation runs. For each run we generate random input parameters and then compute the total number of shipments initiated per month and the number of vessels on the water, which correspond to the values in the lower right-hand corner of Tables 5 and 6 , respectively. Table 7 illustrates that even with significant deviations in the input variables, the results do not differ substantially from our baseline results in Table 5 and 6 . The baseline results are within a factor of two of the $90^{\text {th }}$ percentile in Table 7.

\begin{tabular}{|l|c|c|c|c|c|c|}
\hline & $10^{\text {th }}$ & $25^{\text {th }}$ & $50^{\text {th }}$ & Mean & $75^{\text {th }}$ & $90^{\text {th }}$ \\
\hline Monthly Shipments & 33.5 & 43.8 & 59.1 & 63.2 & 77.5 & 99.4 \\
\hline Vessels on Water & 1.4 & 1.9 & 2.7 & 3.0 & 3.7 & 5.0 \\
\hline
\end{tabular}

Table 7: Percentiles for our two measures over 100000 Monte Carlo simulations

For the remainder of this section, we primarily focus on the velocity and drug capacity of the vessels, as these two parameters have the most significant impact on the final results. There is a large range for these values: as described in Appendix A.2.3, the capacities of the vessels may be up to twice as large as the baseline values in Table 3. If this extreme occurs for all vessel-types, half as many vessels 
would be out on the water and the values in Tables 5 and 6 will decrease by $50 \%$. On the other extreme, many news reports list a load of only a few hundred kilograms. If the average capacity is in fact that low for the non-SPSS vessels, then that would decrease the average capacity by a factor between 2-5 and would significantly increase the amount of vessels on the water. There would be well over 100 shipments initiated per month in this low-capacity scenario.

There is also a large amount of uncertainty regarding velocity. As discussed in Appendix A.2.4, all four types of vessels are capable of faster speeds than those reported in Table 3. However, it is more likely that the average speed over the entire transit will be less than the values in Table 3 , as the smugglers may stop for rest or tactical reasons. In this case the average velocity may be smaller, perhaps reduced by half. Such a situation would double the number of vessels in Tables 5 and 6.

In Section 3.1 we examine the sensitivity of our results to the variability among the capacities and velocities of vessels. In Section 3.2 we analyze the sensitivity to the means of these parameters. Finally, in Section 3.3 we examine modifications to the bivariate distribution in Table 4.

\subsection{Capacity and Velocity Variability}

To generate Tables 5 and 6 in the baseline analysis, we effectively assumed that all vessels of the same type carry the same amount of cocaine (see Table 3). In reality, each vessel may carry a different amount and this can impact the results. For example if 112 metric tons flow along the EastPac corridor each year in SPSS and each carries exactly 5 metric tons, then this equates to 1.87 shipments per month (see Table 5). However, if half of the drugs are transported by a 4-metric ton SPSS and the other half transported by a 6-metric ton SPSS, then 1.94 shipments occur per month. If we had data about capacity variability, then we could produce refined results. However, because such data does not exist we assume all vessels carry the same amount in the baseline

To examine how much this assumption impacts the results, we now look at the simple case where the capacity takes on two possible values. Assume the baseline parameter estimate takes on value $X$ (e.g., 
5mt for the SPSS capacity in Table 3). Instead of assuming all vessels carry $X$, we now assume that with probability 0.5 the capacity is $p^{*} X$, for some fraction $p$, and with probability 0.5 the capacity is $(2-p)^{*} X$. This distribution has the same expected value as the fixed estimate $X$. Smaller values of $p$ imply larger variance in the distribution, which results in more significant deviations from the baseline. For example, if the SPSS capacity is $X=5 \mathrm{mt}$ and $p=0.3$, then with probability 0.5 the SPSS capacity is 1.5 and with probability 0.5 the capacity is 8.5 .

Figure 1 presents the total number of shipments initiated per month (see lower right-hand corner of Table 5) as we vary the parameter $p$ from 0.1 (high variance) to 1 (no variance). We include three curves, which correspond to different hypothesized total amounts of cocaine leaving South America in a year - 500mt, $850 \mathrm{mt}$ and $1200 \mathrm{mt}$ - which average the baseline of $850 \mathrm{mt}$ shown in Table 1 . Note that when $p=1$ the dashed curve has the value 57.4 - the value of our base case in Table 5 .

Figure 2 displays similar results to Figure 1 for the average number of vessels present at any given time in the area of operations (see lower right-hand corner of Table 6). This parameter depends on capacities as well as velocities. Thus, here both capacities and velocity have binary distributions, which are assumed to be independent random variables. Figures 1 and 2 illustrate that the underlying distribution for capacity and velocity can significantly impact the results. 


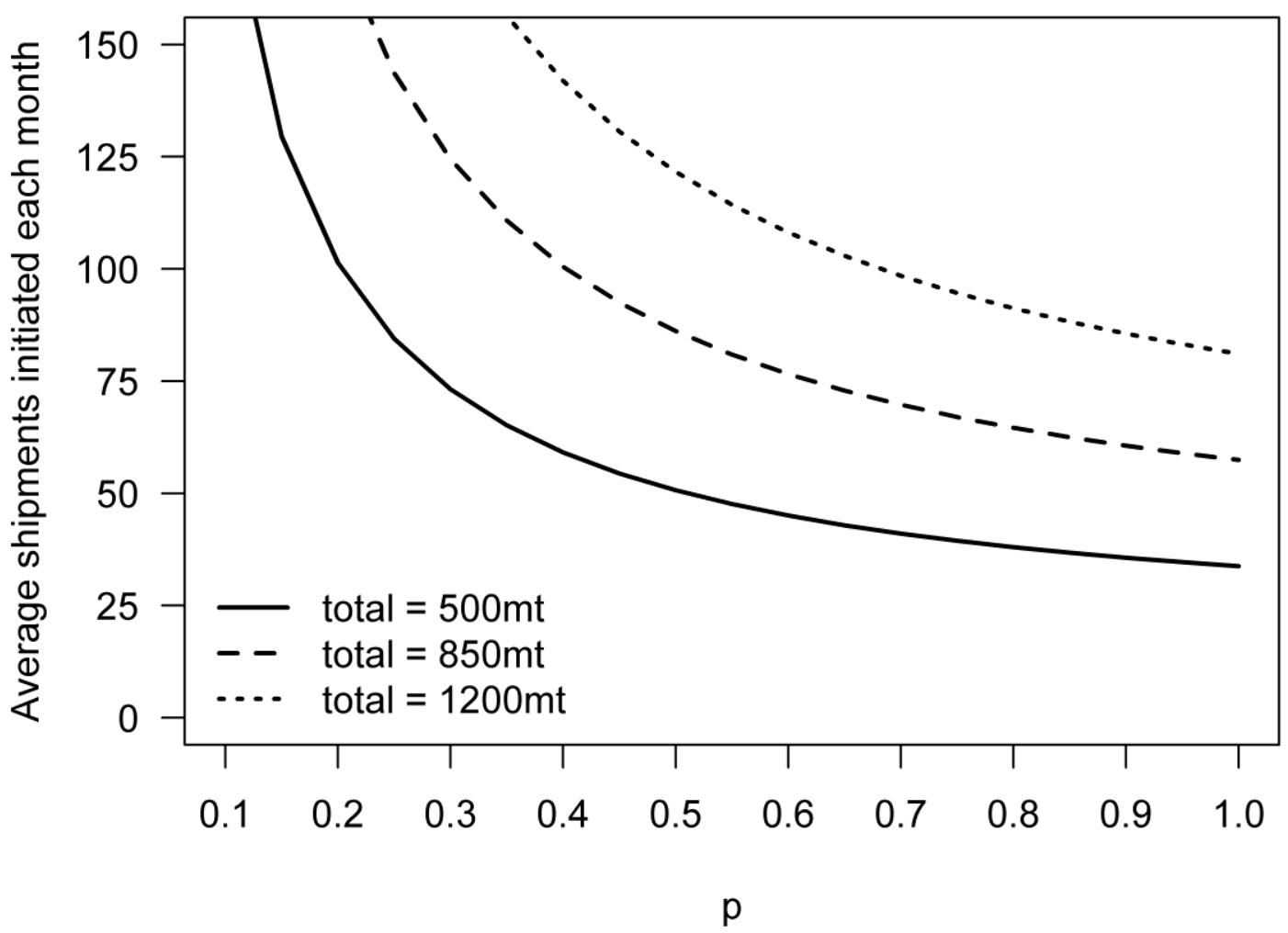

Figure 1: Number of monthly shipments as we change the variance of the capacity. The capacity takes on value $p^{*} X$ with probability 0.5 and $(2-p)^{*} X$ with probability 0.5 , where $X$ is the baseline capacity from Table 3. 


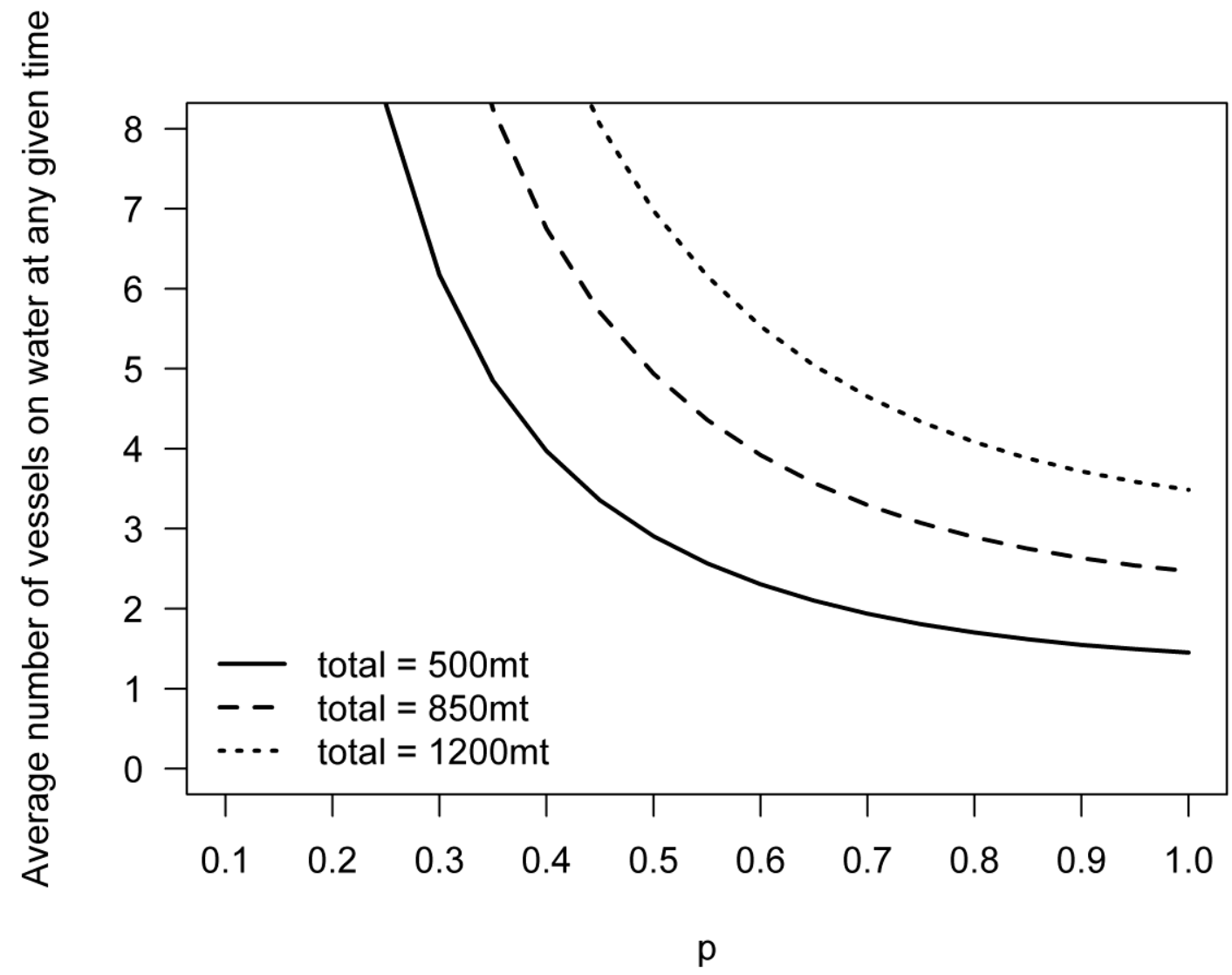

Figure 2: Steady-state number vessels at any given time as we change the variances of capacity and velocity. The capacity and velocity, each takes on value $p * X$ with probability 0.5 and $(2-p)^{*} X$ with probability 0.5 , where $X$ is the baseline parameters from Table 3 .

\subsection{Capacity and Velocity Means}

While in Section 3.1 we examine the effect of capacity and velocity variability, in this section we analyze the sensitivity of the results to changes in the means of these parameters. In the four graphs of Figure 3, we plot the number of monthly shipments vs. the capacity by vessel type. Each figure corresponds to a different vessel type and each figure has three curves. As in Figures 1 and 2, these three curves correspond to different reference amounts of cocaine leaving South America each year. The four 
parts of Figure 3 (one for each type of vessel) illustrates that the monthly shipments increases quickly as we decrease the capacity (especially for Go-fasts and pangas). If our estimates of the capacities are too large, or if traffickers change their tactics to use smaller loads in the future, then the number of monthly shipments could be much higher than the one indicated in the baseline.

\section{Go-fast}

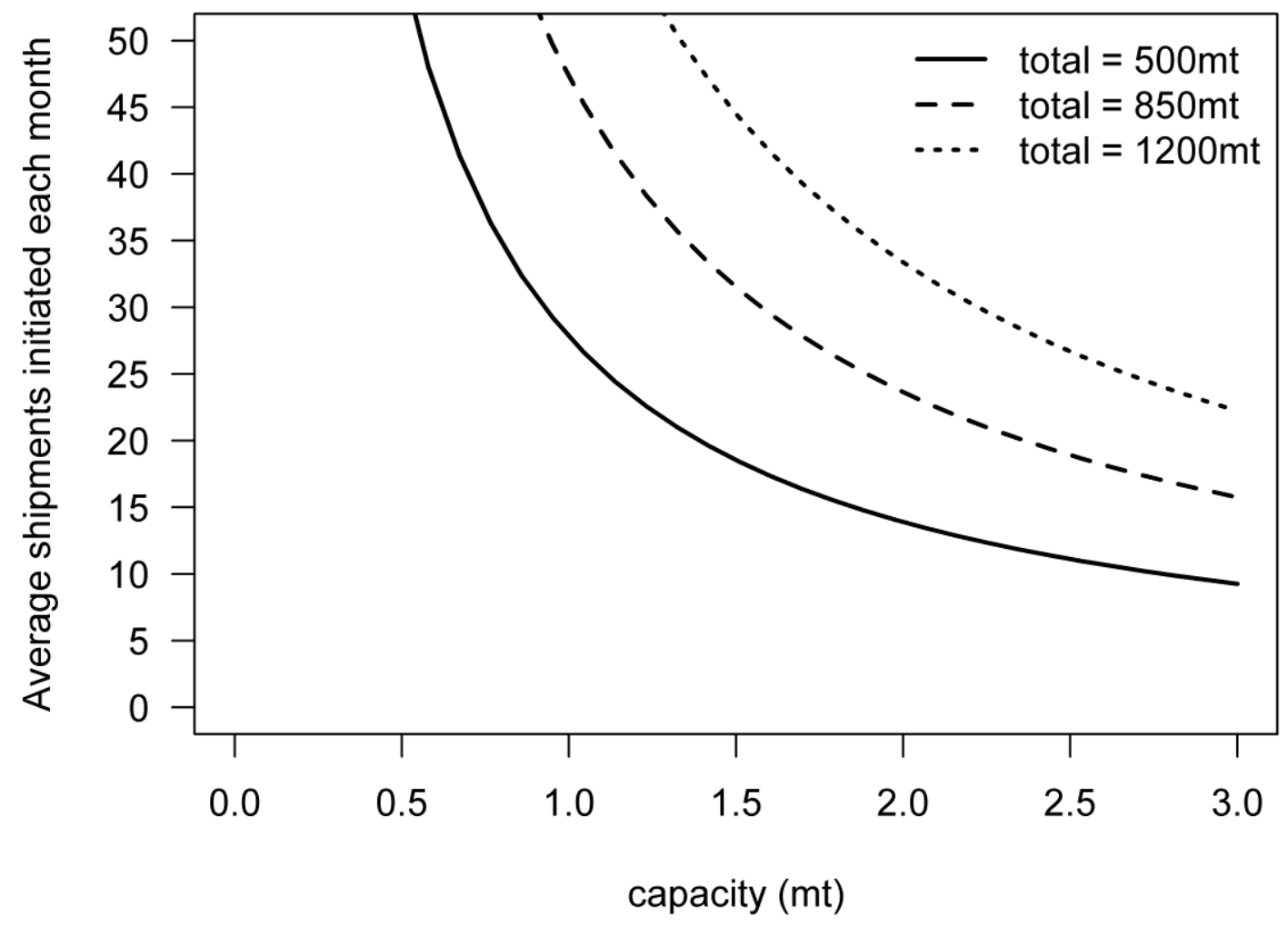

Figure 3a: Number of monthly shipments for Go-fast boats as we vary their capacity, for different amounts of cocaine leaving South America annually 
SPSS

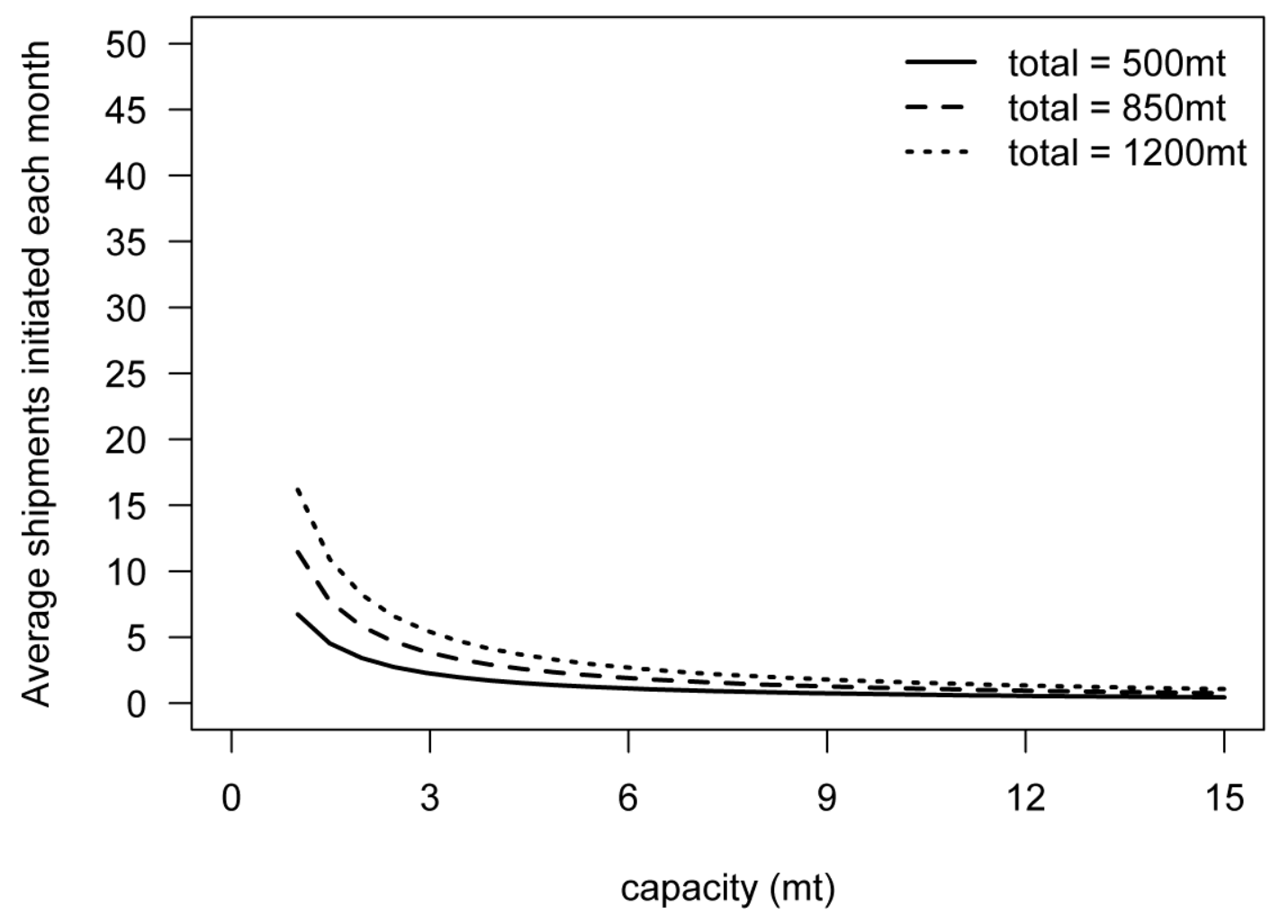

Figure 3b: Number of monthly shipments for SPSS as we vary their capacity, for different amounts of cocaine leaving South America annually 


\section{Fishing}

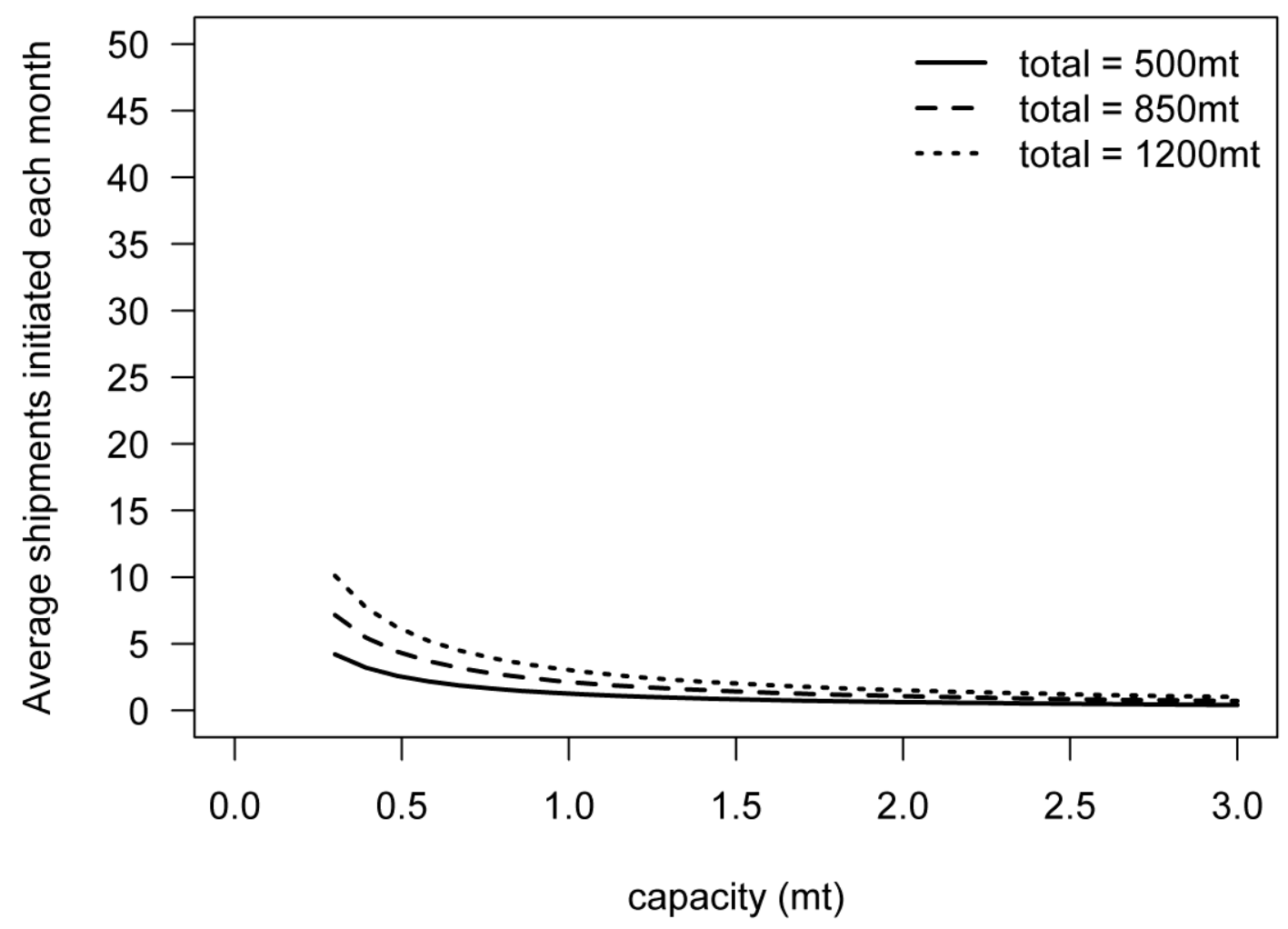

Figure 3c: Number of monthly shipments for fishing boats as we vary their capacity, for different amounts of cocaine leaving South America annually 


\section{Panga}

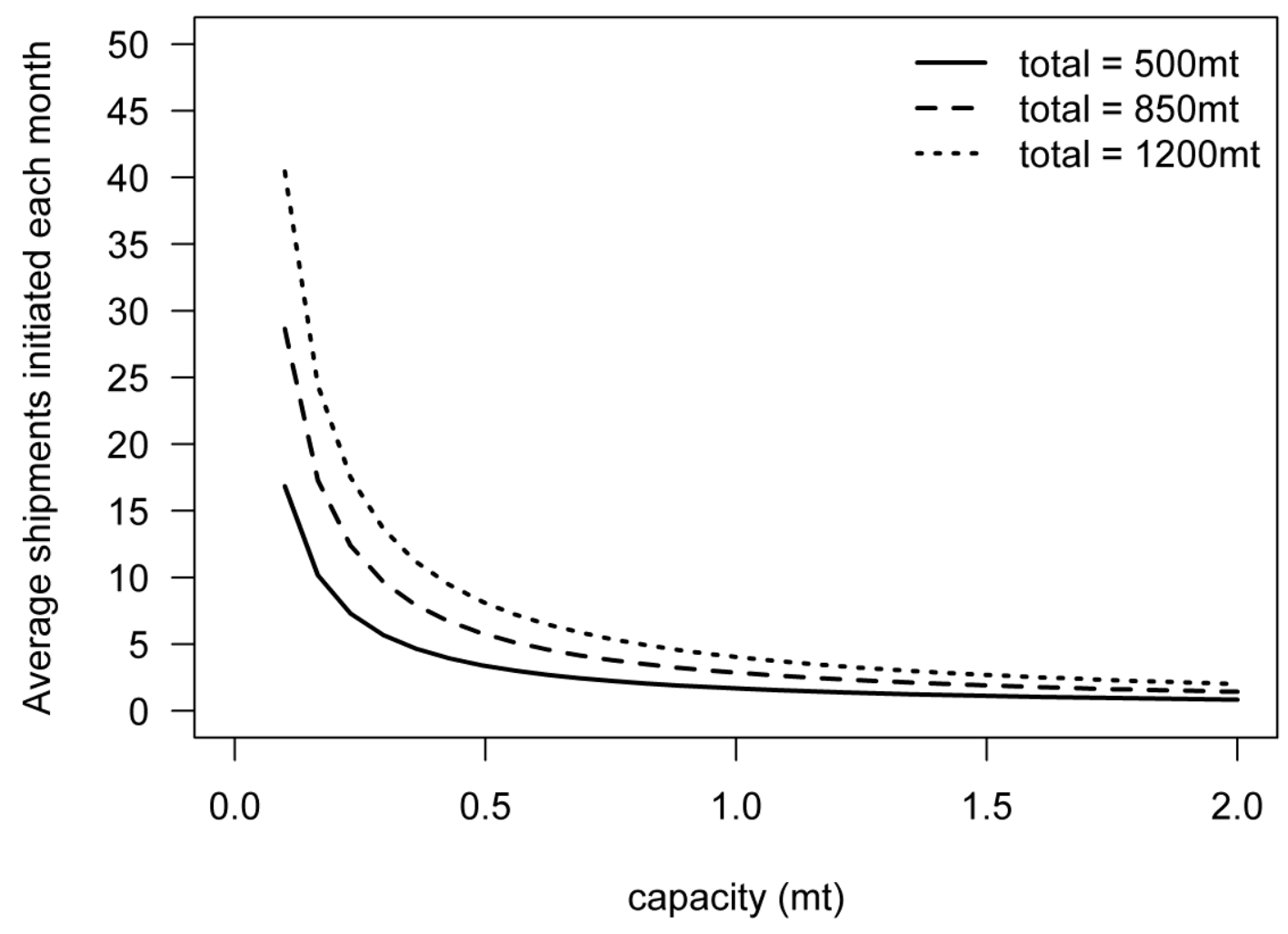

Figure 3d: Number of monthly shipments for pangas as we vary their capacity, for different amounts of cocaine leaving South America annually

Figure 4 presents the average number of vessels on the water at any given time. As this quantity depends upon both velocity and capacity we include both inputs in the figures. We vary the velocity on the $\mathrm{x}$-axis and plot three curves corresponding to three different capacities. Unlike in Figure 3, in Figure 4 we fix the amount of cocaine leaving South America each year to its baseline value of 850mt. We observe that fast, large capacity boats result in substantially fewer vessels on water compared to the baseline in Table 6 (e.g., if a Go-fast boat can carry $3 \mathrm{mt}$ then their average number is reduced from 1.81 to less than 1 - see Figure 4a). On the other hand, slow, small capacity vessels produce over twice as many vessels as our baseline estimates. It is doubtful that the average vessel has both velocity and capacity near the high-end 
of the uncertainty range in Figures 3 and 4. However, with evidence of smaller loads and the possibility that smugglers may purposefully slow or stop during portions of the journey, some of the values on the left-hand portion of Figures 3 and 4 are plausible. Thus it is possible that over 100 shipments initiate every month, and that at any given time there may be over 10 smuggling vessels on the water.

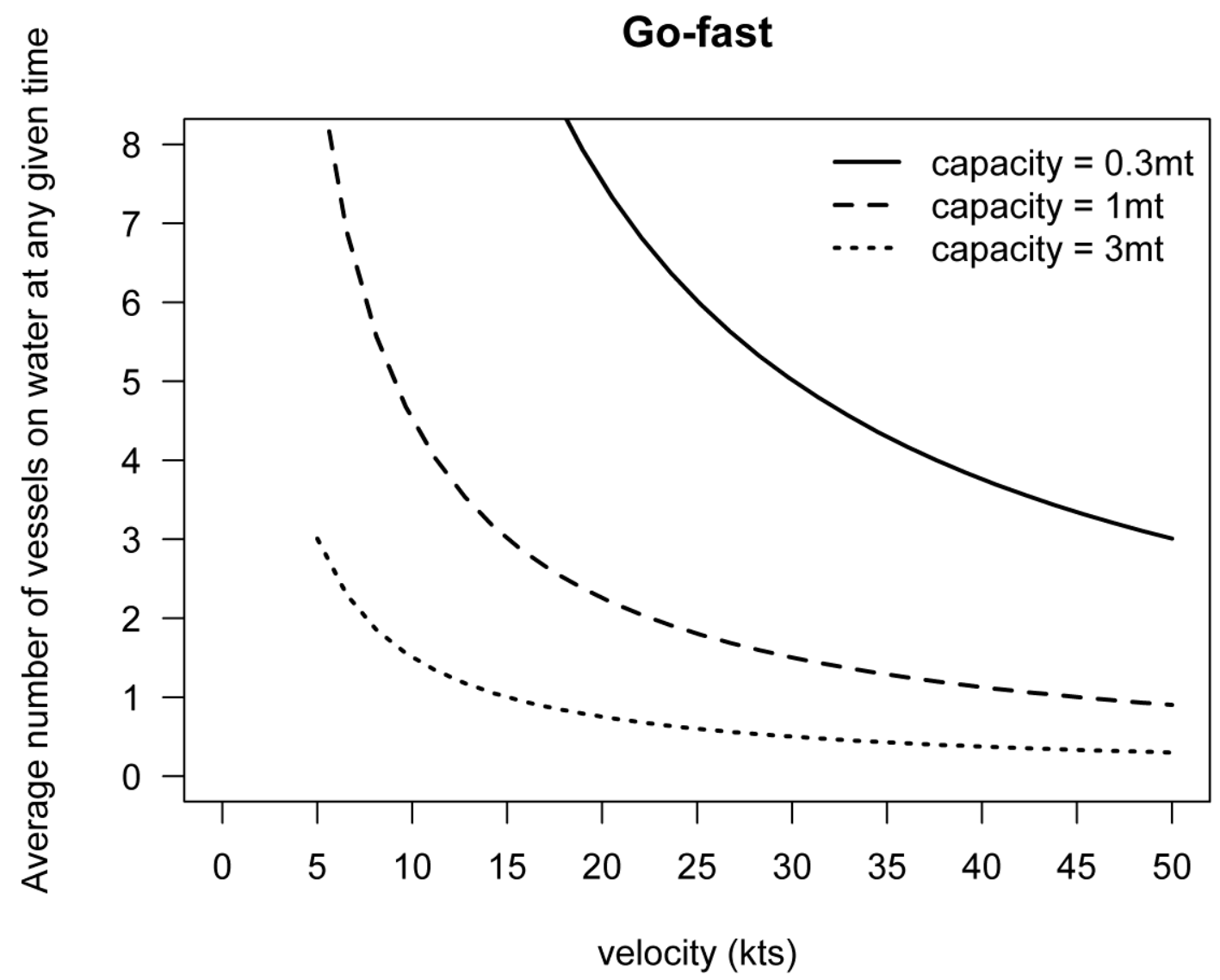

Figure 4a: Number of Go-fast boats on the water as we vary the velocity for different capacities. 


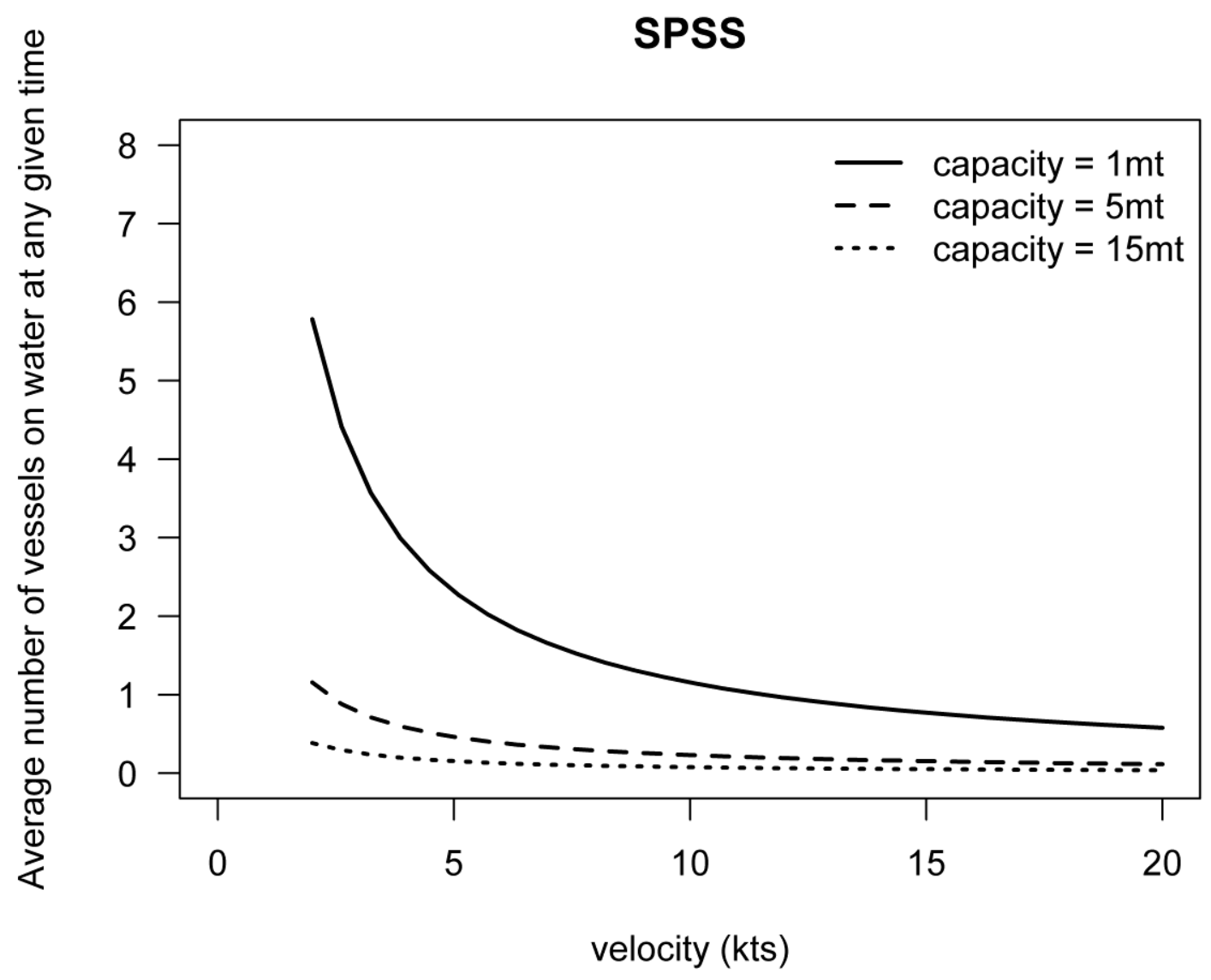

Figure 4b: Number of SPSS vessels on the water as we vary the velocity for different capacities. 


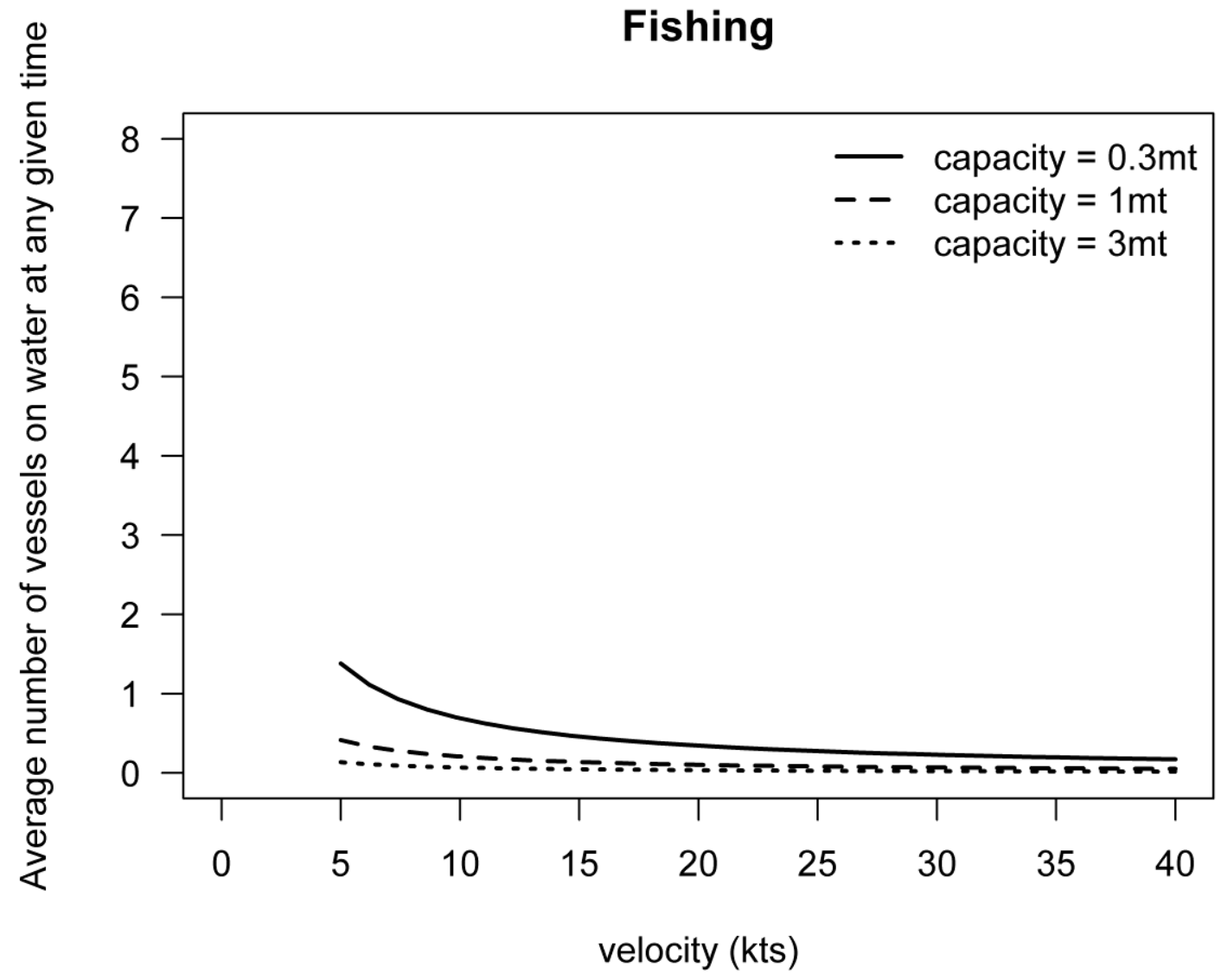

Figure 4c: Number of fishing boats on the water as we vary the velocity for different capacities. 


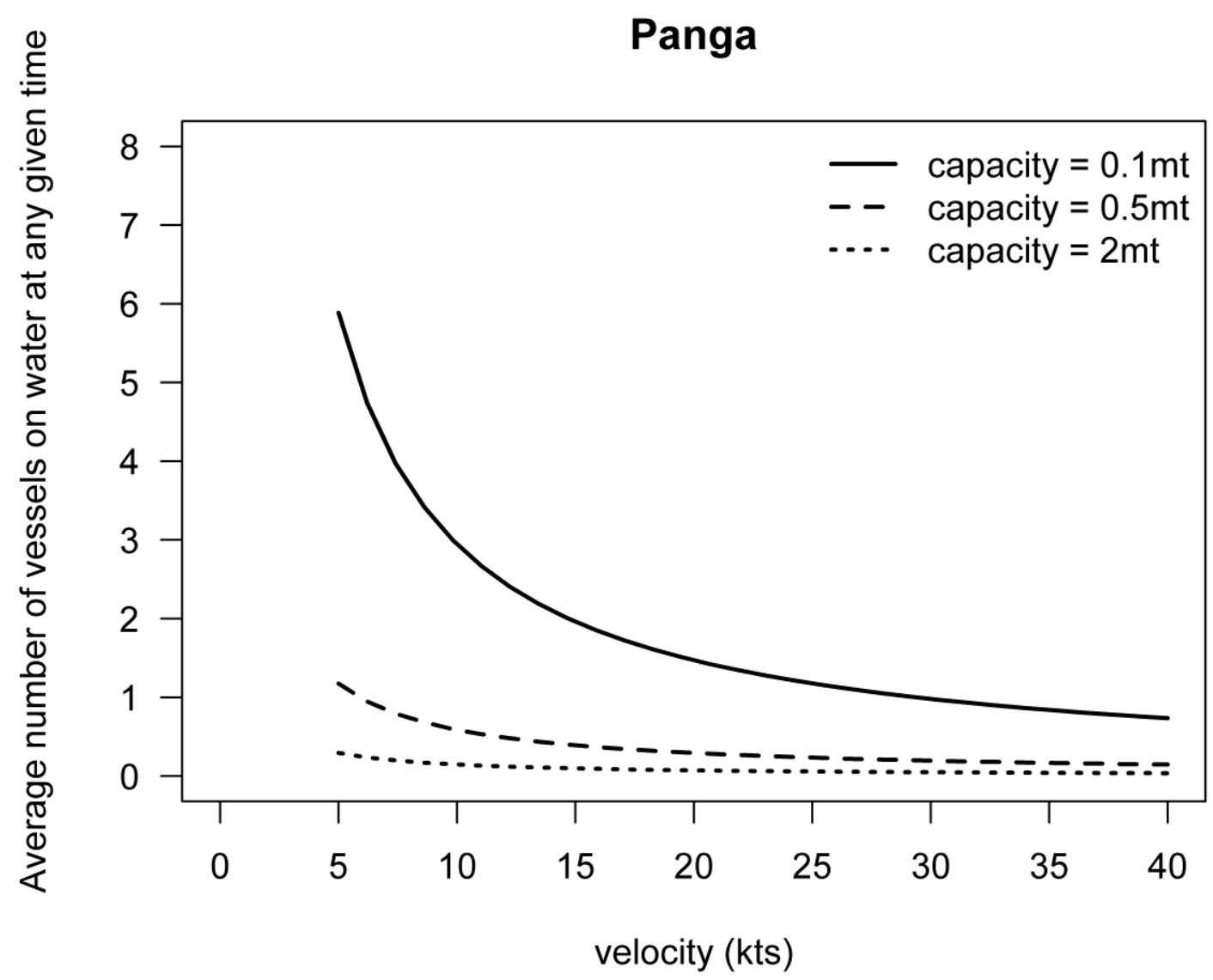

Figure 4d: Number of pangas on the water as we vary the velocity for different capacities.

\subsection{Corridor/Vessel-type Distribution}

We now alter the bivariate distribution in Table 4 to consider two different flow scenarios. In the first scenario, the cocaine that eventually ends up outside the Americas only traverses through the Caribbean. In the second scenario, we assume that the data to generate Table 4 (Figure 2 of ONCDP (2014)) relates to transit-events and not kilograms of cocaine. In this case, the total flow of cocaine carried by SPSS must increase because those vessels carry more per transit than the other vessels.

The deviations from the baseline results in Tables 5 and 6 are minimal when considering these two scenarios. First we assume that $65 \%$ of the cocaine flows to Central and North America and the 
remaining $35 \%$ heads to Europe. Estimates of the fraction of flow to Central and North America range from $55 \%$ to $70 \%$ (see Table A.10 in the Appendix). We assume that the flow heading to Central and North America follows the distribution in Table 4. The 35\% of drugs flow that transit to Europe have the (re-normalized) distribution given by the last two columns of Table 4; in this scenario no drugs marked for Europe flow through the EastPac. The total number of shipments initiated per month increases slightly over the baseline to 58.1, whereas the steady-state number on the water decreases slightly to 2.4 . Obviously more of the flow is concentrated in the Caribbean. This scenario also results in more go-fast and fishing vessels and fewer pangas and SPSS.

If we view Table 4 as representing the distribution of smuggling transits rather than cocaine, we must compute the joint distribution of cocaine flow by weighting each row by capacity. When we do this, the fraction of cocaine transported via SPSS increases significantly to 53\% and the fraction transported by go-fast decreases to $43 \%$. With a much higher prevalence of high-capacity SPSS, the number of vessels decreases to 38 shipments per month with 1.9 on the water at any given time.

Even with fairly substantial changes to the distribution in Table 4, the results do not change as much as they do from changing the capacity and velocity in Sections 3.1-3.2. Efforts should be made to pin down the estimates for velocity and capacity to improve the precision in the final results.

\section{Policy Implications}

The results from our analysis should provide insight for how to allocate assets to search, detect, and interdict DTO vessels. For example Pietz and Royset (2013) formulate a tactical asset allocation model that assigns air assets (e.g., P-3s or P-8s aircraft) to daily missions to search for DTOs based on current intelligence and positions interdiction assets (e.g., Navy frigates) to best-respond if the searchers make a positive detection. For a given number of vessels on the water and the available search and interdiction assets, the Pietz and Royset model outputs a search plan, the probability of successfully detecting each vessel, and the expected amount of drugs interdicted. Our model provides an estimate of 
the number of vessels on the water, and thus can be used in conjunction with the Pietz and Royset model to determine an effective number of search and interdiction assets to assign to counter-drug operations. For example, if our model estimates 4 vessels on water and the Pietz and Royset Model outputs that one searcher can effectively search for 2 vessels, then that suggests the need for 2 active searchers, which means a requirement of 4 search assets to account for down time.

Our results can also be useful to vet informants to check if their information is consistent with the flow estimates. Analysts can use our methodology to estimate the number of shipments initiated per month and the number of vessels on the water when more refined data becomes available. The final estimates should be compared to any existing (and possibly classified) DTO tracking data such as the CCDB. If the flow estimates from our model are much higher than the numbers derived from the data in the CCDB, then there may be a significant amount of unknown flow in the area of operations. We should take efforts to develop more intelligence sources to reduce the unknown flow. If the flow estimates from our model are much lower than the numbers in the CCDB, then a non-trivial amount of the entries in the CCDB may be false. That is, they represent shipments that never occurred. In this case, authorities would need to evaluate the intelligence collection and analysis process and examine the reasons for false shipment records.

\section{Conclusions}

There are several approaches to deal with the flow of cocaine into the US. Arguably the most effective way is to reduce the demand for the drug. The other main option is to disrupt the cocaine supply chain by directing counter-drug efforts at various links of this chain. One type of action is targeting the production stage -- destroying Coca fields and production plants. Another option is to add more friction to the financial network to make it more difficult for money to flow from consumers back to the cartels. This paper is aimed at the transportation phase -- interdicting shipments en-route. To properly plan interdiction operations the military and law-enforcement authorities need information about timing, location, size of drug shipments and the means of transportation that carry the loads of drugs. 
In this paper we focus on maritime transportation and derive estimates for parameters needed for planning maritime drug interdiction efforts. Surprisingly, the estimates for the total number of vessels at sea remain quite robust over a relatively large range of assumptions and estimates regarding the size and distribution of the drug flow, mix of vessel types, and physical characteristics of those vessels. The number of shipments range between four and six dozens a month, and at any given time there are between two and four vessels, of all types, on the high seas. The main caveat relates to velocity and capacity of DTO vessel. It is possible that those values are much lower than our baseline estimates, which could increase the number of monthly shipments to over 100.

Even accounting for uncertainty, our results may underestimate the total number of vessels involved with drug trafficking operations. DTOs may use decoys, mother-ships, and logistics vessels (United States Congress 1987; Milburn 2012). These auxiliary vessels are usually used near the destination as loads are divided and the DTOs attempt to avoid detection by local authorities. It is unknown how frequently DTOs use these auxiliary vessels. While this does not impact our estimates for the total number of shipments initiated from South America, we may underestimate the total number of vessels on the water, especially near the destination regions, by not explicitly accounting for the auxiliary vessels.

To the best of our knowledge this is the first time such estimates are obtained in the open literature. We believe that they will be useful to better plan effective interdiction missions.

\section{References}

L. Alvarez. 2014. In Puerto Rico, cocaine gains access to U.S., New York Times. May 29, 2014.

J. P. Caulkins, B. Kilmer, P. H. Reuter, and G. Midgette, Cocaine's fall and marijuana's rise: questions and insights based on new estimates of consumption and expenditures in us drug markets, Addiction 110(2015) 728-736.

CBS-Miami, Coast Guard intercepts $\$ 58$ million in cocaine off Florida coast, CBS-Miami. September 21, 2011.

CBS-Miami, Coast Guard captures more than a ton of cocaine, CBS-Miami. March 16, 2012. 
Coast Guard News, Coast Guard cutter Midgett returning to Seattle after seizing nearly six tons of cocaine, Coast Guard News. June 30, 2015.

B. Fiegel, The picuda: A wave-breaking go-fast wonder that defies radar detection, Dialogo. September 16, 2014.

W. Gibson, Shifting drug smuggling routes bring contraband to Florida, Sun Sentinel. April 5, 2014.

M. Hodgson, Super-speedboats piloting Colombia's cocaine trade, Christian Science Monitor. September $18,2002$.

J. Kandel, Traffickers using submarines to transport drugs, NBC Los Angeles. September 14, 2012.

B. Kennedy, More than $\$ 110$ million worth of cocaine offloaded by Coast Guard, Local10 Miami. April 15, 2014.

B. Kilmer, S. S. Everingham, J. P. Caulkins, G. Midgette, R. L. Pacula, P. H. Reuter, R. M. Burns, B. Han, R. Lundberg, What America's users spend on illegal drugs: 2000-2010, RAND Corporation. February 2014. A. Milburn. The Evolution of Maritime Drug Trafficking Technology, Maritime Security Challenges Conference Blog, 2012. https://mscconference.wordpress.com/2012/06/22/the-evolution-of-maritime-drugtrafficking-technology/ accessed on 6/11/2016

J. Pietz and J.O. Royset, 2013, Generalized Orienteering Problem with Resource Dependent Rewards, Naval Research Logistics, 60 (2013) 294-312.

Office of National Drug Control Policy, Cocaine smuggling in 2009, ONDCP. October 2010.

Office of National Drug Control Policy, Cocaine smuggling in 2010, ONDCP. January 2012.

Office of National Drug Control Policy, Cocaine smuggling in 2011, ONDCP. 2013.

Office of National Drug Control Policy, Cocaine smuggling in 2012, ONDCP. 2014.

W. Rhodes, C. Dyous, D. Hunt, J. Luallen, M. Callahan, R. Subramanian, M. A. Cala, Drug availability estimates in the United States, ONDCP. 2012.

M. Rodriguez, Coast Guard captures more than a ton of cocaine. CBS-Miami. July 1, 2013.

A. Selsky, Cocaine smugglers using high-tech boats. Washington Post. November 7, 2005.

J. Stavridis, Partnership for the Americas: Western Hemisphere Strategy and U.S. Southern Command, National Defense University Press, Washington, D.C., 2010.

United Nations Office on Drugs and Crime (UNODC), World Drug Report 2011, UNODC, 2011.

United Nations Office on Drugs and Crime (UNODC), Transnational organized crime in Central America and the Caribbean: A threat assessment, UNODC, September 2012. 
United States Coast Guard. 2008. Dangerous self-propelled semi-submersibles (SPSS) proliferating rapidly, DHS, September 2008.

United States Congress, Office of Technology Assessment, The Border War On Drugs, OTA-O-336, March 1987.

United States Senate Caucus On International Narcotics Control, Preventing a security crisis in the Caribbean, United States Senate, September 2012. 


\section{Appendix: Parameter Estimates}

In this appendix we provide the sources and logic behind the estimates in Tables 1-4. As significant uncertainty surrounds many of the estimates, we perform sensitivity analysis in Section 3 to provide a range for the results in Tables 5 and 6 . We stress that we use the best numbers we can find in the open literature. If and when better data become available, our methodology can easily be applied to produce more accurate estimates.

\section{A.1 Cocaine Leaving South America}

There are many estimates of cocaine consumption, seizures, production, and transportation throughout the world. As our focus is on detecting and interdicting DTO vessels in the AO -- Eastern Pacific and the Caribbean Sea -- we need to estimate the flow of cocaine that leaves South America via maritime means. Some of the cocaine flow heading to Asia, Africa, and Europe may not transit through the AO, but we did not find any concrete information about the fraction of that flow. Thus, we assume a "best case" (or "worst case" -- depending on the point of view) scenario where all the cocaine flow from South America that ships via maritime means of transportation passes through the AO. In the sensitivity analysis we consider a reduced total flow from the baseline, which allows for the scenario where some fraction of the cocaine does not transit through the AO. Estimates of the flow out of South America do exist but they vary considerably according to their sources, the identification of the flow destination, and the definition of the substance's level of purity: 100\% pure, export purity, wholesale purity, or retail purity. We consider here the total flow of export quality cocaine crossing the AO, which is the level typical to the cocaine shipped from South America.

In Table A.1 we list the best estimates we could find and the corresponding sources. These sources consider production, consumption, and trafficking data to derive their estimates. The baseline estimate in Table 1, based on 2012 estimates, is 850 metric tons. However, the flow and consumption of cocaine has 
decreased significantly in the first decade of the 21 st century. If these trends continue, the estimate for the current flow in 2016 might be much lower that what appears in Table A.1.

\begin{tabular}{|c|c|c|}
\hline Estimate & Year & Source \\
\hline 1025 & 2006 & Figure FW.4 of ONDCP(2010) \\
572 & 2008 & Figure 1 of ONDCP(2010) \\
$491--1303$ & 2008 & Figure 1 of ONDCP(2010) \\
788 & 2009 & Page 21 of UNODC (2011) \\
709 & 2010 & Figure 1 of ONDCP(2012) \\
833 & 2010 & Figure 1 of ONDCP(2013) \\
633 & 2012 & Figure 1 of ONDCP(2014) \\
849 & 2012 & Figure 1 of ONDCP(2014) \\
\hline
\end{tabular}

Table A.1: Yearly Export Quality Metric Tons Exported from South America

As a sanity check, we also derive an export estimate by starting with US consumption. In 2010 the estimate for US consumption was 150 metric tons of pure cocaine (see Table S.3 in Kilmer et al. (2014)). The United States is believed to consume 0.35 of the cocaine in the world (UNODC 2011; ONDCP 2012, 2014), (see Table A.8). We note that consumption estimates are particular difficult to accurately estimate as they are based on household survey data. Seizures range between 400-700 metric tons (UNODC 2011; ONDCP 2010, 2012, 2013, 2014), (see Table A.9). As only one source lists the seizure amount in 100\% purity, we use 650 metric tons from UNODC (2011). This puts the global production at 1080 metric tons, 430 of which was consumed. This 1080 is close to the 1100 value stated on page 119 of UNODC (2011). $20 \%$ of consumption occurs in South America (see Fig 85 of UNODC (2011)), which leaves approximately 340 metric tons exported for consumption. $60 \%$ of seizures occur in South America (see Fig 83 of UNODC (2011)). Consequently, 260 of the 650 metric tons seized worldwide first leave South America. Putting the pieces together produces an estimate of a total of 600 metric tons of pure cocaine 
exported from South America. Export purity is roughly 0.75 (ONDCP 2012, 2013, 2014)) (see Table A.11), which produces a final estimate of 800 metric tons of export quality cocaine leaving South America. This estimate is consistent with the direct estimates listed in Table A.1.

\section{A.2 Fraction of Drugs via Maritime Conveyances}

Recall that our goal is to estimate the number of drug-smuggling maritime vessels, and thus we discard the cocaine transported via air. The estimates in Table A.2 correspond to the flow of drugs from South America to Central and North America. We use these numbers as our default for all cocaine flowing out of South America because most of the non-Americas cocaine travels via maritime means (UNODC 2011; ONDCP 2013, 2014). Even if the cocaine is flown across the Atlantic, often it is first shipped to an intermediate destination in Central America or the Caribbean (UNODC, 2011). We choose 0.9 as our baseline in Table 1 as it corresponds to the most recent data in 2012.

\begin{tabular}{|c|c|c|}
\hline Estimate & Year & Source \\
\hline 0.9 & 2009 & Figure 4 of ONDCP(2010) \\
0.86 & 2010 & Figure 3 of ONDCP(2012) \\
0.8 & 2011 & Page 13 of United States Senate Caucus On International Narcotics Control (2012) \\
0.87 & 2011 & Page 5 of ONDCP(2013) \\
0.91 & 2012 & Figure 2 of ONDCP(2014) \\
\hline
\end{tabular}

Table A.2: Fraction of Cocaine that leaves Colombia via Maritime Routes

\section{A.2.1 Drug Corridors}

The Cocaine Smuggling documents (ONDCP 2010, 2012, 2013, 2014) present three primary corridors of smuggling: the eastern Pacific, the western Caribbean, and the eastern Caribbean. As Table A.3 shows, 
the distribution of the flow of drugs among these three corridors changes from year-to-year. This occurs as the DTOs adjust to interdiction efforts and enhanced transportation capabilities. The differences in Table A.3 may also result from a bias related to where interdiction efforts focus on in a given year. For example if interdiction efforts shifted to the WCarib from the EastPac from 2009 to 2012, then there would be more known flow in the WCarib relative to the EastPac in 2012 vs. 2009 even if the underlying distribution did not change. We do not have enough information to know whether the numbers in Table A.3 suffer from this reporting bias. We perform sensitivity analysis around the distribution in Table A.3 in Section 3.3. We use the 2012 estimate as our baseline for Tables 2 and 4. We assume that all flow in the AO follows this distribution. It is likely that the flow heading to Central and North America differs from that heading to Europe. We consider such a scenario in Section 3.3.

\begin{tabular}{|c|c|c|c|c|}
\hline EastPac & WCarib & ECarib & Year & Source \\
\hline 0.72 & 0.25 & 0.03 & 2009 & Figure 4 of ONDCP(2010) \\
0.61 & 0.34 & 0.05 & 2010 & Figure 3 of ONDCP(2012) \\
0.53 & 0.42 & 0.05 & 2011 & Page 4 of ONDCP(2013) \\
0.59 & 0.33 & 0.08 & 2012 & Figure 2 of ONDCP(2014) \\
\hline
\end{tabular}

Table A.3: Distribution of Cocaine Flow along Different Corridors

Figure 4 of ONDCP (2012), Figure 5 of ONDCP (2012), and Figure 4 of ONDCP (2014) provide more detailed information about the flow of cocaine across various routes in each corridor. This allows us to generate an estimate for the distance a smuggler travels along each route. In Table A.4, we present information on various routes derived from Figure 4 of ONDCP (2014). Each route begins in Colombia and ends in the country in the Route column. Figure 4 of ONDCP (2014) provides an estimate for the amount of drugs transported along the route for 2012, which we replicate in Table A.4. We compute the distance along each route using standard mapping procedures. Taking a weighted average, by drugs transported, of the distances along each route of a given corridor produces the estimates in Table 2 . 


\begin{tabular}{|c|c|c|c|}
\hline Corridor & Route & Drugs Transported & Estimated Route Distance \\
\hline EastPac & Panama & $82 \mathrm{mt}$ & $350 \mathrm{~nm}$ \\
EastPac & Costa Rica & $59 \mathrm{mt}$ & $700 \mathrm{~nm}$ \\
EastPac & Guatemala & $22 \mathrm{mt}$ & $1000 \mathrm{~nm}$ \\
EastPac & Mexico & $55 \mathrm{mt}$ & $1300 \mathrm{~nm}$ \\
\hline WCarib & Panama & $22 \mathrm{mt}$ & $350 \mathrm{~nm}$ \\
WCarib & Costa Rica & $25 \mathrm{mt}$ & $550 \mathrm{~nm}$ \\
WCarib & Guatemala & $69 \mathrm{mt}$ & $800 \mathrm{~nm}$ \\
WCarib & Mexico & $7 \mathrm{mt}$ & $1000 \mathrm{~nm}$ \\
\hline ECarib & Hispaniola & $68 \mathrm{mt}$ & $500 \mathrm{~nm}$ \\
\hline
\end{tabular}

Table A.4: Characteristics of Cocaine Flow Along Different Routes in 2012. Derived from Figure 4 of

ONDCP (2014)

\section{A.2.2 Vessel-Type}

The Cocaine Smuggling in series (ONDCP 2010, 2012, 2013, 2014) also provides a breakdown of types of vessels used by the DTOs along the three corridors. We focus on go-fast, SPSS, fishing vessels, and pangas. The distribution for four years appears in Table A.5, which illustrates the preference for go-fast vessels. We use the 2012 values as our base-case in Tables 3 and 4. Trans-Atlantic flow often transits on container ships (UNODC 2011; ONDCP 2013, 2014). Thus our analysis may overstate the flow on the smaller vessels in the AO. 


\begin{tabular}{|c|c|c|c|c|c|}
\hline Go-fast & SPSS & Fishing & Panga & Year & Source \\
\hline 0.57 & 0.26 & 0.16 & 0.00 & 2009 & Figure 4 of ONDCP(2010) \\
0.72 & 0.12 & 0.05 & 0.10 & 2010 & Figure 3 of ONDCP(2012) \\
0.63 & 0.24 & 0.08 & 0.04 & 2011 & Page 5 of ONDCP(2013) \\
0.74 & 0.18 & 0.03 & 0.05 & 2012 & Figure 2 of ONDCP(2014) \\
\hline
\end{tabular}

Table A.5: Distribution of Cocaine Flow by Vessel-Type

\section{A.2.3 Capacity}

There is very little concrete unclassified information on the capacity of drug-smuggling vessels. While such information may exist in government, military, or law enforcement databases, we did not find any detailed data. Various reports list possible capacities (UNODC 2011; ONDCP 2013, 2014), but there is no systematic study of the average load. We augment these reports with news accounts of interdiction events (see for example: Fiegel (2014); Gibson (2014); Alvarez (2014)). In Table A.6 we present several estimates from various sources for the four vessel types. The baseline values in Table 3 are representative of the estimates in Table A.6. The exception is the fishing vessel category. With so little information, we use the same capacity as a go-fast for the baseline estimate. 


\begin{tabular}{|c|c|c|}
\hline Type & Estimate & Source \\
\hline Go-fast & 0.5 & Rodriguez (2013) \\
\hline Go-fast & $0.5-0.75$ & Alvarez (2014) \\
\hline Go-fast & $0.5-1$ & Gibson (2014) \\
\hline Go-fast & $0.5-2$ & Hodgson (2002) \\
\hline Go-fast & $1-2$ & Fiegel (2014) \\
\hline Go-fast & 1.5 & CBS-Miami (2012) \\
\hline Go-fast & 2 & ONDCP $(2013,2014)$, CBS-Miami (2011) \\
\hline SPSS & $5-10$ & UNODC (2012) \\
\hline SPSS & 6 & Kandel (2012) \\
\hline Fishing vessel & 2.4 & Kennedy (2014) \\
\hline Panga & 0.3 & ONDCP (2012) \\
\hline Panga & 0.75 & Coast Guard News (2015) \\
\hline
\end{tabular}

Table A.6: Drug Capacity for Various Types of Vessels in Metric Tons

\section{A.2.4 Velocity}

As with capacity, there is very little information about how fast drug-smuggling vessels travel. There are reports that list maximum speed or average speed of a particular vessel. However, just because a go-fast can travel comfortably at 25kts in most sea-states, does not mean it will do so constantly over the entire duration of the trip. There are reports that smugglers will idle for periods to thwart detection (Selsky 2005; Gibson 2014). As an example, the smugglers may stop during the day and cover the vessel with a blue tarp to limit visual detection capabilities. In this case the average velocity may be half the standard cruising velocity of the vessel. This will have a significant impact on the results. As there is so much uncertainty with the velocity, we perform additional sensitivity analysis for this estimate in Sections 3.1-3.2. 


\begin{tabular}{|c|c|c|}
\hline Type & Estimate & Source \\
\hline Go-fast & 50 & Hodgson (2002) \\
Go-fast & 50 & Selsky (2005) \\
Go-fast & 25 & ONDCP (2014) \\
\hline SPSS & 10 & United States Coast Guard (2008) \\
SPSS & 13 & Kandel (2012) \\
\hline
\end{tabular}

Table A.7: Velocity for Various Types of Vessels in Knots

\section{A.2.5 Other Parameters}

In this section we list other parameters that we use to perform additional analysis. Table A.8 lists the fraction of cocaine consumed by the United States. We use this parameter in Section A.1 to estimate the amount of cocaine exported from South America by starting with US consumption.

\begin{tabular}{|c|c|c|}
\hline Estimate & Year & Source \\
\hline 0.36 & 2009 & Page 16 of UNODC(2011) \\
0.4 & 2009 & Figure 8 of ONDCP(2014) \\
0.37 & 2010 & Figure 8 of ONDCP(2014) \\
0.46 & 2010 & Figure 8 of ONDCP(2012) \\
0.34 & 2011 & Figure 8 of ONDCP(2014) \\
0.32 & 2012 & Figure 8 of ONDCP(2014) \\
\hline
\end{tabular}

Table A.8: Fraction of Cocaine Consumed By the United States 
To generate the consumption estimate in Section A.1 requires knowledge of the amount of cocaine seized or lost throughout the world. Table A.9 provides several estimates.

\begin{tabular}{|c|c|c|}
\hline Estimate & Year & Source \\
\hline 650 & 2009 & Page 119 of UNODC(2011) \\
540 & 2009 & Figure 6 of ONDCP(2010) \\
450 & 2010 & Figure 7 of ONDCP(2012) \\
425 & 2011 & Figure 9 of ONDCP(2013) \\
450 & 2012 & Figure 10 of ONDCP(2014) \\
\hline
\end{tabular}

Table A.9: Worldwide Losses and Seizures of Cocaine in Metric Tons

In Table A.10 we list the fraction of flow heading to North and Central America. The remaining cocaine ends up in Europe, Africa, Asia, or Australia. In the base-case scenario we assume that the cocaine flow that eventually lands outside the Americas still follows the corridors defined in Section A.2.1 in the initial phases of the transit while in the AO. In Section 3.3 we modify this assumption.

\begin{tabular}{|c|c|c|}
\hline Estimate & Year & Source \\
\hline 0.57 & 2009 & Page 119 of UNODC(2011) \\
0.7 & 2011 & Figure 7 of ONDCP(2014) \\
0.58 & 2012 & Figure 7 of ONDCP(2014) \\
\hline
\end{tabular}

Table A.10: Fraction of Cocaine Flow to North and Central America

Finally in Table A.11 we list the export purity of cocaine. Several reports state values in units of $100 \%$ purity, and thus we use the values in Table A.11 to generate the equivalent export purity. 


\begin{tabular}{|c|c|c|}
\hline Estimate & Year & Source \\
\hline 0.76 & 2008 & Page 1 of ONDCP(2010) \\
0.76 & 2010 & Page 9 of ONDCP(2012) \\
0.73 & 2011 & Page 6 of ONDCP(2013) \\
\hline
\end{tabular}

Table A.11: Export Purity of Cocaine Leaving South America 